\title{
Mesenchymal stem cells for vascular regeneration
}

\author{
Ngan F Huang ${ }^{1}$ and Song $\mathrm{Li}^{2, \dagger}$ \\ 1 Stanford University, Division of Cardiovascular Medicine, Stanford, CA, USA \\ 2University of California Berkeley, Department of Bioengineering, MC 1762 Berkeley, CA 94720-91762, \\ USA Tel: + 15106662799 Fax: +1 510666 3381; E-mail: song_li@berkeley.edu
}

\begin{abstract}
Mesenchymal stem cells (MSCs) have tremendous potential for regenerative medicine, and have been researched for the treatment of cardiovascular diseases. MSCs are a promising cell type because of their ease of isolation and expansion, their multipotency and their low immunogenicity. However, in order to fully utilize the therapeutic potential of MSCs, it is important to understand the intrinsic property of MSCs and the role of the microenvironment in modulating MSC behavior and function. Microenvironmental factors such as mechanical cues, soluble factors and matrix properties not only regulate MSC differentiation, but also modulate MSC signaling to the surrounding environment. Understanding the properties of MSCs and the role of the microenvironment will be beneficial for developing in vivo therapies for the construction of tissue-engineered vascular grafts and the treatment of ischemic cardiac tissues.
\end{abstract}

\section{Keywords}

angiogenesis; bone marrow; extracellular matrix; mechanical strain; mesenchymal stem cell; myocardial infarction; shear stress; tissue engineering; vascular graft

In the USA, cardiovascular disease is a serious cause of mortality and morbidity. Three-quarters of all cardiovascular-related deaths are attributed to atherosclerosis and the resulting arterial clogging, myocardial infarction (MI) and stroke [1]. In 2005, it was reported that 469,000 coronary artery bypass procedures and over one million percutaneous interventions were performed [1]. Despite the improvement in overall quality of life using existing treatments, there is still a prevalent need for new treatments that can enhance blood perfusion to ischemic tissues, improve the patency of small-diameter bypass grafts and provide alternative options when there is no suitable autologous artery or vein for bypass grafting.

With the advent of technological advances in stem cell therapeutics and vascular tissue engineering, the ability to regenerate the vasculature may be one step closer to reality. Stem cells have the unique ability to give rise to progeny with more specialized cell function, as well as those that retain their stem cell state. Among the various types of stem cells, mesenchymal stem cells (MSCs) are a promising cell source because of their high expansion ratio, ease of

\footnotetext{
$\dagger$ Author for correspondence:.

For reprint orders, please contact: reprints@futuremedicine.com

Financial \& competing interests disclosure

The authors thank the support by the grants from National Institute of Health (HL HL078534 and HL083900). The authors have no other relevant affiliations or financial involvement with any organization or entity with a financial interest in or financial confl ict with the subject matter or materials discussed in the manuscript apart from those disclosed.

No writing assistance was utilized in the production of this manuscript.
} 
isolation, ability to differentiate into vascular cell types and release proangiogenic factors and low immunogenicity. However, in order to develop novel therapies to restore dys-functional vasculature, it is necessary to understand how the microenvironment may affect MSC differentiation, signaling and organization into functional units and tissues for vascular therapy. As illustrated in Figure 1, the microenvironment includes chemical factors, such as soluble signaling factors, physical cues, such as matrix topography and matrix rigidity, and mechanical stimulation, in the form of shear stress and strain [2].

In this article, we will discuss the role of the microenvironment in modulating MSC phenotype and the potential of MSCs for vascular regeneration, with emphasis on the engineering of vascular grafts and neovasculature formation for treatment of MI.

\section{Characterization of MSCs}

Interest in MSCs began over 130 years ago when Cohnheim, a German pathologist, suggested that the bone marrow gave rise to fibroblast-like cells during the repair process [3,4]. Later in the 1970s, Friedenstein and colleagues demonstrated that whole bone marrow contained a heterogeneous population of adherent cells that could later generate bone and cartilage deposits [5]. These results were later confirmed and further investigated by several groups of pioneers in the field, who demonstrated that the adherent cells were multipotent and could differentiate towards a variety of lineages, including cardiovascular cell types [6-10]. Owing to the various definitions of MSCs used throughout the literature, the working definition of MSCs that will be used throughout this article is a class of adherent cells with spindle-shaped morphology, self-renewal capacity and ability to give rise to daughter cells with more specialized function.

MSCs can be found in numerous organs, including the bone marrow, fat, blood, liver and spleen [2,11-13], with bone marrow being the most characterized origin. Within the bone marrow, MSCs are adherent cells that contribute to the niche of non-adherent hematopoietic stem cells (HSCs). Although MSCs occupy only $0.01 \%$ of the total population of nucleated cells in bone marrow, in vitro they have a high expansion ratio of over 1 million-fold, while maintaining multi-lineage differentiation capacity $[8,14]$. They can be routinely expanded for over ten passages in media containing defined components (i.e., StemPro® MSC Serum Free Medium, Invitrogen, Carlsbad, CA, USA) or pre-screened fetal bovine serum.

Techniques to purify MSCs include Percoll® gradient centrifugation, selection by the adherent mononuclear cell population on tissue culture-treated Petri dishes or by immunophenotyping. There is no specific marker that can identify MSCs from other cell types, but MSCs generally express markers including STRO-1 (a stromal cell surface antigen), CD29 (integrin $\beta 1$ ), CD44 (receptor for hyaluronic acid and matrix proteins), CD105 (endoglin) and CD166 (cell adhesion molecule). On the other hand, they lack the expression of CD14 (monocyte surface antigen), CD34 (HSC surface antigen) and CD45 (leukocyte surface antigen) $[15,16]$. In some cases, such cell surface markers have been empirically used to isolate MSCs by fluorescenceactivated cell sorting (FACS) or magnetic-activated cell sorting. However, this surface marker profile is not standardized for all MSCs owing to the heterogeneity of cell phenotype from various origins and species. For example, CD34 appears to be expressed in MSCs derived from mice, but are absent in human MSCs [17]. Nevertheless, these surface markers are commonly used for characterizing MSCs.

MSC differentiation towards vascular phenotypes can be distinguished by the expression of experimentally identified specific markers or by functional assays. For smooth muscle cell (SMC) differentiation, markers specific to this cell type include cytoskeletal proteins $\alpha$-smooth muscle actin (SMA), smooth muscle myosin, SM22 and calponin [18]. On the other hand, endothelial cell (EC)-specific markers include platelet-endothelial cell adhesion molecule 1 (CD31), vascular endothelial (VE)-cadherin and EC-synthesized glycoprotein von Willibrand 
Factor (vWF). Functionally, ECs are also characterized by their ability to form tube-like structures in matrigel and uptake acetylated low-density lipoproteins.

As a result of various tissue sources for the generation of MSCs, differences may exist in terms of their growth characteristics, gene expression and differentiation potential. With respect to expansion rates, one study compared the growth curves between Ficoll-gradient centrifugationderived human MSCs from the umbilical cord, bone marrow and adipose tissue [19]. The authors showed that the frequency of colony formation was highest in cells derived from adipose tissue and lowest in those derived from umbilical cord. On the other hand, umbilical cord-derived MSCs appeared to have the highest proliferation capacity, whereas the bone marrow-derived cells had the lowest capacity. Another study examining the gene-expression profiles of human bone marrow-derived MSCs reported that the top 36 of 50 most expressed tags by these cells were also expressed in umbilical cord-derived MSCs [20]. Although these two origins of MSCs shared similar immunophenotypes, the bone marrow-derived MSCs had higher expression of markers associated with osteogenesis, namely biglycan, TSC22, CD44 and vitronectin. On the other hand, umbilical cord-derived MSCs appeared to express higher levels of genes associated with angiogenesis mediated by IL-1 and TNF- $\alpha$ pathways, including CXCL6 (GCP-2), IL-8 (or CXCL8), ILIRLILG and MMP1 (interstitial collagenase). These data implicate potential differences in the molecular signature and growth patterns of MSCs from various origins. However, it is unclear how these differences may modulate their differentiation capacity towards vascular lineages.

The advantages of MSCs as a cell source for vascular regeneration include the ease and accessibility of MSCs by a bone marrow aspiration in the iliac crest or lipoaspiration from liposuction procedures, high expansion potential and reproducible phenotypic characterization by FACS analysis [8].

One unique advantage of MSCs is their potential for allogenic cell delivery in immunocompetent patients. Their immune-privileged characteristic is partially due to the lack of expression of major histocompatibility complex (MHC) II antigens that are responsible for immune rejection, although MHC II expression could be induced by IFN- $\gamma$ stimulation [21]. In addition, MSCs lack the expression of co-stimulatory molecules that activate T cells, including CD40, CD80 and CD86 [22]. MSCs have immunomodulatory effects of inhibiting the proliferation of $T$ cells and B cells, and suppressing the function and maturation of dendritic cells [23-25]. These effects are mediated by both cell-cell contact and by the release of soluble factors that include TGF- $\beta 1$, HGF, IL-10 and prostaglandin E-2 [23,26,27]. Since MSCs do not appear to acquire MHC II cell surface antigens during adipogenic, chondrogenic and osteogenic differentiation, it is possible that MHC II antigens would not be expressed upon cardiovascular differentiation [21].

\section{Soluble chemical factors \& MSCs}

Soluble chemical factors are multifaceted in their ability to modulate cell behavior and function (Table 1). In particular, they can signal vascular cells and MSCs to grow, proliferate, migrate, differentiate and modulate cellular release of chemical factors. The factors that influence MSCs include VEGF, PDGF, basic FGF (bFGF) and TGF- $\beta$. Conversely, MSCs can also release some of these growth factors to facilitate tissue regeneration in the microenvironment (Table 2).

VEGF-A is commonly produced by vascular and tumor cells, and has been shown to be expressed by MSCs as well. The release of VEGF from MSCs can promote the recruitment of ECs for angiogenesis in ischemic tissue and endothelialization in injured arteries. VEGF-A homodimers usually bind to VEGF receptor 1 (flt) or receptor 2 (fl k-1). However, recent studies show that MSCs do not express VEGF receptors, but VEGF can promote MSC proliferation and migration by activating PDGF receptors in MSCs [28]. In addition, PDGF, 
bFGF and TGF- $\beta$ are two other angiogenic growth factors that modulate MSC activity. As shown in Table 1, these factors play a role in inducing cell migration, proliferation and differentiation into vascular cell types. For example, VEGF, PDGF and bFGF appear to stimulate MSC migration [28-31]. VEGF and PDGF can induce MSC differentiation into an endothelial phenotype [29,32], whereas TGF- $\beta$ signals SMC specification [33-36]. Proteomic profiling analysis revealed that TGF- $\beta$ decreased the expression of gelsolin to promote the assembly of contractile filaments [33]. Furthermore, transactivation of genes could also induce some similar effects as soluble factors, as shown by the effect of MSC proliferation after adenoviral transduction of VEGF [29]. Together, these results indicate that soluble factors can modulate MSC phenotype.

\section{Role of mechanical factors}

Mechanical stimulation plays an important role in maintaining the phenotype of vascular cells. The endothelium is continuously subjected to fluid shear stress caused by blood flowing across this lining, and both the endothelial and smooth muscle layers experience cyclic strain resulting from pulsatile stresses from the beating heart. The role of mechanical factors on vascular cell behavior and phenotype has been well-documented [37-41], but the ability of mechanical stimulation to induce phenotypic changes in MSCs towards vascular lineages has only recently been investigated. Among the various forms of mechanical stimulation, shear stress and strain models are commonly studied.

\section{- Role of shear stress on MSCs}

Under physiological conditions, the endo thelium in arteries experiences shear stress within the range of 10 to 20 dynes $/ \mathrm{cm}^{3}[42,43]$. The shear stress that results from blood flow appears to modulate EC function by activating downstream signaling pathways. To study the effect of shear stress on cell behavior, both in vitro and in vivo systems can been used. The advantage of the in vitro system is the ability to control the magnitude and direction of shear stress, whereas in vivo models are a step closer to translating in vitro findings to clinically relevant diseases [44]. Fluid shear stress is commonly modeled in vitro by laminar flow using a parallelplate chamber as a 2D culture model, or in the case of interstitial flow, by a porous 3D matrix.

To date, studies of shear stress on MSC migration, proliferation and vascular differentiation remains limited in number. Table 3 summarizes the results from published findings related to shear stress effects on MSC phenotype and behavior. In one study using STRO-1-expressing rat bone marrow stromal cells, 36-h shear stress $\left(\sim 14 \mathrm{dyn} / \mathrm{cm}^{2}\right)$ stimulation by pulsatile flow increased the number of smooth muscle myosin heavy chain-expressing cells, although SMA protein levels was not significantly different when compared with the static control group [45]. In another study, shear stress applied to murine C3H/10T1/2 embryonic mesenchymal progenitor cells led to induced expression of endothelial markers such as CD31, vWF and VEcadherin at the mRNA and protein level after $12 \mathrm{~h}$ of steady shear stress levels of $15 \mathrm{dyn} /$ $\mathrm{cm}^{2}$ [46]. Shear stress could also stimulate endothelial function, including the uptake of acetylated low-density lipoproteins and formation of capillary-like structures on matrigel.

\section{- Role of mechanical stretch on MSCs}

Physiologically relevant levels of strain in blood vessels range from 5 to $30 \%$ strain and 30 to 90 cycles per min [37]. In 2D culture, strain is often studied by uniaxial or equiaxial models in which cells are cultured on elastic substrates such as poly(dimethylsiloxane) (PDMS), which can be repetitively stretched to controllable strain magnitudes and frequencies. For 3D stretch models mimicking vascular environments, equiaxial stretch conditions can be simulated by embedding cells in a tubular matrix and then stretching the construct from the luminal side. 
The effect of strain is well-characterized in vascular cell types, but not for MSCs [47]. As summarized in Table 3, we have previously shown that for human bone marrow-derived CD105- and CD166-expressing MSCs, 5\% cyclic equiaxial strain at 60 cycles per min for 24 $\mathrm{h}$ downregulates SMA and SM22 $\alpha$, whereas cyclic uniaxial strain transiently increases the expression of these markers [48]. However, in another study in which rat bone marrow-derived adherent cells were exposed to $10 \%$ cyclic uniaxial strain at 60 cycles per min for 7 days, the expression of SMA and h1-calponin was induced [49]. The seemingly opposing results may be attributed to differences in stimulation time, species-specific response or stem cell phenotype. In the former report, immunophenotypically characterized human cells were studied for a period of $24 \mathrm{~h}$ at $5 \%$ equiaxial strain, whereas the latter report utilized rat adherent cells without immunophenotypic characterization and examined the effect of $10 \%$ cyclic uniaxial strain for 7 days. Consequently, it is unclear which specific factors may be attributed to these conflicting results.

In addition to global gene-expression changes, uniaxial strain induces cell realignment in the perpendicular direction, relative to the direction of stretch. To assess whether uniaxial strain could promote MSC differentiation if cell orientation was restricted, we cultured human bone marrow-derived CD105- and CD166-expressing MSCs on microgrooves in the directions parallel or perpendicular to 5\% uniaxial strain. Notably, global changes in MSCs were observed only when MSCs were kept aligned in the direction of uniaxial strain [50]. DNA microarray analysis showed an upregulation of h1-calponin expression, alterations in cell signaling and increases in cell proliferation. Together, these studies suggest that physiological levels of stretch can modulate MSC gene expression, cell alignment, proliferation and phenotype towards those that are consistent with smooth muscle characteristics.

\section{- Role of multimodal mechanical stimulation on MSCs}

To mimic the dynamic physiological environment, multimodalities of mechanical stimulation have been studied in well-controlled in vitro environments. O'Cearbhaill et al. cultured bone marrow-derived CD73- and CD105-expressing human MSCs in the presence of pulsatile pressure $\left(40-120 \mathrm{mmHg}\right.$ ), radial distention of $5 \%$ and a shear stress of $10 \mathrm{dyn} / \mathrm{cm}^{2}$ at a frequency of 60 cycles per min for up to $24 \mathrm{~h}$ [51]. Histological analysis revealed that the majority of MSCs responded to the mechanical stimuli by aligning within $20^{\circ}$ to the direction of flow and by adopting a compact cell size, as is characteristic of ECs. However, gene expression and immunofluorescence analysis of both the stimulated and static groups reported that the cells did not express EC marker vWF factor on either the mRNA or protein level. Instead, the mechanically stimulated cells exhibited greater levels of smooth muscle-associated markers SMA and calponin in comparison to static samples. These results implicate the potential of MSCs as a cell source for the generation of SMCs, although the morphology and orientation appeared to resemble that of ECs.

In addition to stimulating differentiation, multimodalities of mechanical strain and shear could also affect matrix deposition by MSCs. When ovine bone marrow-derived CD45- and CD14negative MSCs were cultured on poly (glycolic acid) (PGA) and poly(l-lactic acid) (PLLA) scaffolds in the presence of both cyclic stretch (60 cycles per min) and shear stress ( 1 dyne/ $\mathrm{cm}^{2}$ ) for 3 weeks, a 75\% higher collagen content was observed compared with cells with stretch, shear or static control groups [52]. These results suggested that that combined stretch and shear could stimulate MSCs to remodel the matrix microenvironment, which has applications for accelerating tissue formation. These results together demonstrate the effect of shear stress and strain in modulating stem cell phenotype and behavior. 


\section{Role of matrix factors}

Matrix materials are often used in the development of engineered vascular tissue constructs, but our understanding of the role of cell-matrix interactions is not well understood. To engineer matrix environments for cellular ingrowth, a number of naturally derived (i.e., collagen, laminin, fibronectin, Matrigel ${ }^{\mathrm{TM}}$, hyaluronic acid and fibrin) and synthetic polymers (i.e., PLLA and PGA) have been used [53-62]. Besides serving as a temporary scaffold for cell attachment, migration and survival, they may also modulate cell behavior and function based on the matrix rigidity and physical structure [63,64].

\section{- Role of matrix rigidity}

Physiological matrix rigidity, a bulk property of the material that is characterized by the Young's modulus, varies within three orders of magnitude from soft tissues of the brain to hard tissues of the bone [65]. In particular, matrix rigidity plays an important role in cardiovascular applications, as cardiovascular cells respond to changes in matrix stiffness due to injury or disease such as MI or atherosclerosis. To utilize MSCs as a potential cell source for cardiovascular treatments, it is therefore important to understand the effects of matrix rigidity on MSC function and behavior as well.

The ability to sense matrix rigidity relies on mechanosensing structures in the cell such as integrins and focal adhesions. Integrins are transmembrane glycoproteins that serve as mediators of communication between the intracellular and extracellular environment from the inside-out or outside-in [66]. Structurally, they consist of an $\alpha$ - and $\beta$-subunit that assembles together in different combinations to form heterodimers. In human MSCs, $\alpha 1$ through $\alpha 6$ and $\beta 1$ through $\beta 4$ are reportedly expressed [67,68]. Binding of the extracellular domain of integrin mediates cell-cell and cell-extracellular matrix (ECM) adhesion, whereas binding of the cytoplasmic domain to intracellular ligands can activate signaling pathways or modulate cytoskeletal assembly. Related to integrins are focal adhesions, a complex of cytoskeletal proteins and enzymes that can bind the cytoplasmic domain of integrins or to actin [69]. Together, integrins and focal adhesions mediate the transduction of external cues that regulate cell morphology, migration, proliferation and differentiation.

To study the role of matrix rigidity, Pelham and Wang developed a method to vary the stiffness by changing the concentration of acrylamide and bis-acrylamide crosslinker used to form the matrix, while maintaining the same chemical composition [70]. This model enabled wellcontrolled studies of the effects of rigidity independent of chemical composition. Their studies, which assessed the role of substrate rigidity on fibroblast migration, led to striking observations that rigidity alone could modulate cell morphology and spreading area. In particular, they found that cells on softer substrates had lower spreading areas and faster migration rates, in comparison to cells on more rigid substrates [71]. Besides controlling cell spreading, matrix rigidity can also modulate the directionality of migration, as cells tend to migrate from soft (14 $\mathrm{kPa})$ to hard (30 $\mathrm{kPa})$ substrates [72].

Besides modifying the behavior of differentiated cells, rigidity also has profound effects on the fate of MSCs. Engler et al. demonstrated that human bone marrow-derived MSCs differentiated on polyacrylamide substrates towards osteogenic, muscular and neuronal lineages according to the physiological rigidity of respective tissues [73]. In particular, soft matrices that mimic brain tissue stimulated neurogenesis, whereas rigid matrices that resemble the stiffness of bone induced osteogenesis. These findings were supported by transcriptional profiling data showing upregulation of neurogenic markers on soft gels $(0.1-1 \mathrm{kPa})$, myogenic markers on intermediate gels $(11 \mathrm{kPa})$ and osteogenic markers on stiff gels $(34 \mathrm{kPa})$. Lineage specification by matrix rigidity appeared to be dependent on non-muscle myosin II, as demonstrated by the loss of lineage specificity when cells were exposed to blebbistatin, an 
inhibitor of non-muscle myosin II. However, further research is necessary to understand the role of matrix rigidity in modulating MSC morphology, migration and vascular lineage specification.

\section{- Role of matrix patterning}

In addition to matrix rigidity, matrix patterning can also direct cell organization and differentiation [63]. Therefore, to mimic physiologically ordered vascular tissues, micropatterning and nanopatterning tools can enable well-controlled studies of restricted cell alignment. Soft lithography is a convenient method to generate micropatterns for biological applications. The desired pattern can be generated by photolithography onto a silicon wafer, which can be transferred to an elastomeric material such as PDMS [74]. Cells grown directly on the PDMS stamp would be subjected to the topographical features. Alternatively, the patterns on the PDMS stamp can be transferred onto other substrates by microfluidic patterning or microcontact printing.

Using microfludic patterning of collagen I in parallel microchannels, we have previously shown that vascular SMCs can align according to the direction of the channels [75]. Furthermore, the proliferation rate of SMCs decreased on substrates with channels that were 20 and $30 \mu \mathrm{m}$ wide, compared with nonpatterned substrates. In addition to SMCs, skeletal myoblasts could also align according to topographically patterned PDMS and form globally aligned myotubes in the direction of the microchannels [76]. Myotube length was significantly longer on micropatterned substrates than that on nonpatterned substrates, suggesting a potential role of micropatterning as a tool for generating physiologically aligned cellular constructs for tissue-engineering applications.

While the effects of micropatterning on vascular and muscle cells have been studied, the effect of micropatterning on MSCs remains to be elucidated. McBeath et al. employed micropatterned islands of fibronectin to probe the role of cell shape in mediating human bone marrow-derived MSCs towards adipogenic and osteogenic differentiation [77]. Notably, adipogenesis was associated with small $\left(1024 \mu \mathrm{m}^{2}\right)$ islands in which the cells remained rounded in morphology, whereas large $\left(10,000 \mu \mathrm{m}^{2}\right)$ islands preferentially induced osteogenic differentiation and an adherent morphology. It was further demonstrated that actin assembly and Rho GTPase mediate the differentiation of MSCs towards adipogenic and osteogenic lineages.

In addition to microscale features, nanoscale features can also restrict cellular alignment, behavior and differentiation. Nanofibrous matrices can be prepared by electrospinning, a process that generates nanoscale fibers formed by high-voltage electrostatic field [78]. In the electrospinning process, a thin stream of electrically charged polymer solution travels to a collector plate as it evaporates, forming fibrous polymer strands [78]. When a rotating drum is used as the collector plate, parallel-aligned fibrous networks can be generated [79]. Alternatively, randomly oriented fibers can be stretched to generate aligned fibers.

We have utilized electrospinning technology to generate parallel-aligned PLLA substrates to create aligned skeletal myoblasts, neurite outgrowth and MSCs [76,80,81]. In particular, we have shown that CD105- and CD166-expressing human bone marrow-derived MSCs cultured on aligned PLLA nanofibers with diameters similar to that of collagen fibrils $(500-1000 \mathrm{~nm})$ remain viable and align in the direction of the nanofibers in vascular tissue-engineering applications [81]. Moreover, the cellular organization of MSCs was similar to that of SMCs on native arteries, suggesting that the nanofibrous substrates could mimic the structure native collagen matrix upon which SMCs are grown, which can be used to construct tissue-engineered vascular grafts. 


\section{Therapeutic potential of MSCs for vascular regeneration}

\section{- Vascular grafts}

In 2005, almost 500,000 coronary artery bypass procedures were performed [1]. Despite the improvement in overall quality of life by bypass procedures, there is still a growing need to engineer off-the-shelf vascular graft replacements to eliminate the need for donor vessels, which have a 35\% 10-year failure rate. Synthetic acellular vascular grafts, which can be made of various biomaterials such as poly(ethylene terephthalate) and polyurethane $[82,83]$, have been restricted to sizes larger than $5 \mathrm{~mm}$ in diameter owing to the heightened risk of thrombosis and occlusion associated with smaller graft diameter sizes. As a result, engineering living blood vessels is a promising alternative.

Blood vessels consist of three cell layers, namely an endothelial lining in the innermost layer, vascular SMCs in the medial layer and a fibroblast adventitial outermost layer. Models of living vascular grafts have been developed to contain cells alone, matrix alone, or the combination of cells, soluble factors and matrix [81,84-88], and the grafts may consist of multiple layers or single layer of cells and/or matrix (Figure 2). For example, Weinberg et al. showed that a piece of blood vessel can be constructed with ECs as inner lining and SMCs in collagen gel, supported by a Dacron mesh [84]. L'Heureux et al. demonstrated the feasibility of generating trilaminar vascular grafts without the use of a scaffold. The authors grew sheets of SMCs and wrapped them around a tubular support to produce the medial layer. Then, in a similar manner, they wrapped a sheet of fibroblasts around the SMC layer to generate the adventitial layer, before ECs were finally seeded in the lumen [86]. The same approach has recently been used to construct a bilayered vascular grafts containing ECs and fibroblasts [89]. Niklason et al. demonstrated the feasibility of engineering vessels by culturing ECs and SMCs in a tubular PGA porous scaffold in a bioreactor [87]. The engineered vessels were mechanically robust and could respond to pharmacological agents like native vessels. When implanted in vivo, the engineered arteries remained patent for up to 24 days.

Whilst the use of ECs and SMCs for generating vascular conduits would require patientspecific cell isolation, MSCs are a favorable alternative cell source because of their ability to be delivered allogenically as an off-the-shelf therapy. Studies to date provide encouraging results that suggest that MSC-seeded grafts may be a feasible therapeutic option as a vascular conduit (Table 4). In one study, green fluorescence protein (GFP)-labeled rat bone marrowderived MSCs that express CD90 and CD73 were cultured on polyurethane vascular prosthesis and assessed for their ability to differentiate into vascular lineages in vivo [90]. The cells were found to be organized in a multicellular structure that mimics that of native arteries 2 weeks after implantation in mice. The cells co-expressed GFP and SMC markers, suggesting that the in vivo setting induced smooth muscle protein maturation. MSC-seeded grafts were also more highly endothelialized than acellular grafts to prevent thrombosis. However, the electrophysiological profile of MSC-differentiated SMCs appeared to be different from that of mature SMCs. These results suggested that only partial differentiation of MSCs into SMCs were achieved by in vivo implantation.

We have recently shown that CD105- and CD166-expressing human bone marrow-derived MSCs that were cultured on aligned electrospun nanofibrous PLLA conduits can promote efficient in vivo infiltration of vascular cells and ECM remodeling [81]. In vivo transplantation of the MSC-seeded or acellular conduits as interpositional grafts in rat common carotid arteries showed that the cell-seeded grafts enabled long-term patency with well-formed layers of endothelial and smooth muscle layers. Both the cell-seeded and acellular grafts were shown to have extensive collagen deposition, but only cell-seeded grafts developed an elastic lamina adjacent to the lumen, implicating that the ECM and cellular components of MSC-seeded grafts closely resembled those in native vessels. Interestingly, only few MSCs could be found in the 
grafts after explantation at 7 days after transplantation, suggesting that the long-term retention or differentiation of MSCs may not be necessary to confer the therapeutic benefits of antithrombogenesis and vascular remodeling.

The patency of MSC-seeded grafts may be related to the anti-thrombogenic properties conferred by MSCs [81]. Our in vitro studies demonstrated that platelet adhesion and aggregation was notably higher on SMCs than on MSCs or ECs, indicating that MSCs are comparable to ECs in their ability to confer antiplatelet adhesion properties. The mechanism of resisting platelet aggregation appears to be related to MSC cell surface heparin sulfate proteoglycans. The disruption of heparin sulfate proteoglycans by heparinase treatment led to increased platelet adhesion. This study demonstrated an important role of heparin sulfate proteoglycans on MSCs in resisting platelet adhesion.

Recent studies have utilized genetic modification of MSCs to better mimic the function of vascular cells. Kanki-Horimoto et al. transduced rat bone marrow-derived MSCs with an adenovirus harboring endothelial nitric oxide synthase (NOS), which is normally released by the endothelium to prevent thrombogenesis, to better mimic ECs [91]. While culturing the modified or naive MSCs onto small-caliber expanded polytetrafluoroethylene vascular prostheses, they monitored NOS activity based on the conversion of radiolabeled arginine to citrulline and found that the citrulline levels were increased in modified MSCs, in comparison to the naive cells. Furthermore, NOS activity could be blocked by the NOS inhibitor, $N(\mathrm{G})-$ nitro-l-arginine methyl ester. This study highlights a promising technology for developing grafts with improved patency rates.

Tissue-engineered vascular grafts have also been shown to be mechanically durable. One study assessed the mechanical properties and therapeutic potential of a tubular scaffold consisting of a compact polyurethane layer sandwiched by porous PLGA on either side [92]. The burst strength of vascular grafts ranged from 160 to $183 \mathrm{kPa}$, which was similar to the burst pressure in veins $(\sim 223 \mathrm{kPa})$ [86]. In addition, the compliance was $0.57-53.80 \% / 100 \mathrm{mmHg}$, which was higher than that of conventional Dacron grafts. This tubular scaffold was next seeded with canine bone marrow stromal cells purified by Ficoll gradient centrifugation and implanted for up to 24 weeks in the canine abdominal aorta. Histological analysis of the vessels after explantation demonstrated full patency and differentiation towards EC and SMC lineages. These results suggest that this trilaminar scaffold favors mechanical strength and patency. Together, these studies demonstrate the therapeutic potential of MSCs and polymer scaffolds for developing vascular conduits that confer mechanical strength, patency and vascular differentiation potential.

Besides MSCs, endothelial progenitor cells (EPCs) can be used to cover the luminal surface of vascular grafts and prevent thrombus formation [93-98]. However, this approach may only be used autologously owing to the potential immune responses and the limited expansion capability of human ECs and EPCs. Alternatively, if appropriate adhesion or receptor ligands are available on the vascular graft, EPCs in the circulating blood can attach and cover the luminal surface $[99,100]$. Modification of vascular grafts to recruit EPCs or MSCs from circulating blood will be an attractive approach to facilitate the endothelialization of the vascular graft.

\section{- MSCs for treatment of MI}

Besides generating vascular conduits, MSCs have been utilized for treatment of MI, which results when blood supply to the heart is blocked, leading to cardiomyocyte cell death. The pathological remodeling process that results includes scar tissue formation and thinning of the free wall, which contribute to the impairment of cardiac performance [101-103]. To repair MI tissue, angiogenesis is initiated to restore blood supply to the tissue. The process of 
angiogenesis begins when supporting cells known as pericytes are first removed from the branching vessel. Next, the endothelial basal lamina and ECM degrade, and are replaced by a new matrix that attracts EC migration and proliferation. The ECs then form a tube-like structure that recruits pericytes and SMCs to the abluminal surface, forming a new vascular branch [104].

Angiogenesis is a highly organized process that is mediated by soluble chemical cues. For example, VEGF induces vascular hyperperme-ability, endothelial migration and proliferation. FGF mediates endothelial migration, proliferation and tube formation, and TGF- $\beta$ plays an important role in matrix remodeling and vessel restabilization [104]. Since these soluble factors play an important role in vascular remodeling and angiogenesis, they have become widely studied as potential agents to modify MSC behavior and function for vascular repair.

Various cell types have been used to repair MI tissue, including fetal cardiomyocytes [105], skeletal myoblasts [106], embryonic stem cells [107] and MSCs [108]. The modes of delivery into ischemic tissue include systemic or local routes including local injection, systemic injection or the placement of a local patch. Systemic delivery into the circulation can be advantageous because of minimal invasiveness, but the efficiency of directed homing may be limited. On the other hand, local delivery to the ischemic tissue is preferable to ensure cell transplantation to desired tissue locations, although accessing the myocardium may be surgically invasive. Cells can also be delivered concomitantly with polymers, which provide structural support and mediate cell survival and proliferation. Furthermore, the polymers can be adapted for delivering other factors, including cytokines, plasmids, viruses and drugs [109].

For the repair of MI, numerous studies report a therapeutic effect of delivering MSCs to improve cardiac repair by stimulating neovascularization and vascular differentiation (Table $4 \&$ Figure 3). For example, the delivery of density-gradient purified bone marrow-derived canine MSCs for treatment of chronic myocardial ischemia led to significant improvement in ejection fraction and vascular density in the cell-treated group, and MSCs were also found to express EC and SMC markers [110]. Schuleri et al. delivered density-gradient purified bone marrow-derived porcine MSCs in allogenic models of MI and monitored myocardial blood flow by first-pass perfusion MRI over 8 weeks [111]. Their results demonstrated a significant improvement in myocardial blood flow over the first week in MSC-treated animals, compared with placebo-treated animals and untreated animals, but this improvement was not sustained at 4 and 8 weeks. On the other hand, global cardiac function was improved at week 8 . This finding suggests that early tissue perfusion appears to precede improvement in cardiac function. To address the therapeutic potential of MSCs derived from patients with ischemic heart disease, CD105- and CD106-expressing bone marrow derived-MSCs from the diseased patients were delivered to immunocompromised mouse models of MI [112]. MRI assessment and immunohistochemical analysis showed that, after 14 days, the ejection fraction was significantly higher in the group receiving cell treatment. In addition, the MSC-treated group had increased vascularity and reduced thinning of the infarct scar, along with the generation of MSC-derived cells that expressed endothelial marker vWF. The therapeutic benefits of improved cardiac function and cardiomyocyte survival after MSC treatment has been confirmed by others as well [113-115].

Some reports raise concerns over the incidence of MSC differentiation into cardiovascular cell types as artifacts of cell fusion [116,117]. One study utilizing Cre/lox recombination to detect cell fusion events of murine bone marrow-derived MSCs showed that the cells fused in vitro with neural progenitors [116]. In the same study, in vivo bone marrow transplantation demonstrated that the cells fused with hepatocytes, Purkinje neurons and cardiac muscle, but no evidence of differentiation could be detected. However, other evidence points to 
differentiation as a true phenomenon. For example, Kajstura et al. infused c-kit-expressing bone marrow-derived cells from male transgenic mice that expressed enhanced GFP (eGFP) into female recipient hearts [118]. Using both immunofluorescence detection of eGFP and fluorescence in situ hybridization for $\mathrm{X}$ and $\mathrm{Y}$ chromosomes, the authors detected newly formed cardiac and vascular cells that had one set of the $\mathrm{X}$ or $\mathrm{Y}$ chromosome as well as expression of eGFP. This study suggests that the cells differentiated rather than fused with host cells. Based on these studies, the relative contribution of cell fusion and differentiation is unclear.

Preservation of endogenous ECM and intercellular junctions also appears to be involved in promoting therapeutic benefits after MSC delivery. Miyahara et al. derived rat MSCs from adherent adipose tissue for transplantation as a patch onto the epicardial surface of infarcted hearts [119]. Their results showed that the sheets engrafted and grew in thickness, containing MSC-derived vascular cells, undifferentiated cells and few cardiomyocytes. The cell sheets also stimulated the formation of vascular structures originating from the host tissue, suggesting that MSCs could stimulate angiogenesis by acting through a paracrine mechanism. Another study comparing the therapeutic effect of rat MSCs derived from bone marrow by Percoll gradient centrifugation in either dissociated or sheet fragment form for repair of the infarcted heart reports significant enhancement of vascular density and graft/host cell connection for the cell sheet-treated animals [120]. The MSC sheet fragments were found to be aligned along the interstices of the injection sites, whereas very few cells were retained in the dissociated cell group.

The mechanism by which MSCs improve neovascularization after MI is unclear. Increasing reports provide evidence that MSCs act through a paracrine mechanism, in addition to differentiating into vascular lineages that directly contribute to vascular function. MSCs have been shown to secrete angiogenic factors such as VEGF and bFGF that may stimulate angiogenesis in ischemic tissues [121]. Furthermore, Tang et al. showed evidence that MSCtreated infarcts had higher levels of stromal cell-derived factor- $1 \alpha$, a stem cell homing factor, as well as reduced levels of proapoptotic protein Bax, when compared with rats receiving media treatment [122]. Therefore, it is likely that MSCs are involved in inducing angiogenesis and promoting survival cues in ischemic tissues.

In addition to cells alone, MSCs delivered in conjunction with polymers have resulted in therapeutic improvement. In one recent study, a cardiac patch was formed by embedding human bone marrow-derived CD44-negative MSCs in collagen I matrix [123]. Transplantation of the construct as an epicardial patch for immunocompetent rats after MI led to the reduction of left ventricular interior diameter at systole, thickening of the anterior wall and improvement in cardiac function as assessed by fractional shortening. Interestingly, the cells were not detectable at 4 weeks after transplantation, suggesting that sustained cell retention was not necessary for cardiac improvement. A similar study of transplanting an epicardial patch consisting of multilayered rat bone marrow-derived MSCs in a decellularized pericardial scaffold also led to improved heart function and the formation of MSC-derived neovasculature [124]. We have also delivered bio-compatible matrices to the infarcted myocardium as acellular matrices or in conjunction with cells $[64,125]$. We demonstrated that local injections of collagen I, Matrigel and fibrin into the infarcted rat myocardium induced significantly higher capillary density, in comparison to saline control treatment, and could stimulate cell infiltration [64]. Whether or not the induction may be related to matrix-mediated activation of angiogenic factors or prosurvival cues needs to be further examined. Together, these studies illustrate the therapeutic potential of MSCs for increasing neovascularization and vascular differentiation, as well as improving cardiac function. 
Another area of research interest is in the improvement of MSC viability after transplantation into the ischemic myocardium. Owing to the low survival rate of transplanted cells, Mangi et al. showed that the overexpression of Akt1 could improve MSC survival in vitro and in vivo [126]. Using rat CD34-negative bone marrow-derived MSCs that were retrovirally transduced with Akt1 containing a GFP reporter construct, the authors found that in vivo delivery of these modified cells maintained both higher cell retention and higher viability at $24 \mathrm{~h}$ after cell delivery into the infarcted heart, in comparison to cells modified with GFP reporter construct alone. In addition, the cells improved cardiac function and were found to express cardiac phenotypes. Related approaches to enhance MSC survival in the ischemic heart by either hypoxic preconditioning or by genetic modification of bcl 2 or angiogenin expression have also resulted in higher cell retention in vivo [127-129]. These studies highlight the utility of genetic modification or preconditioning to improve transplant viability.

\section{Conclusion}

In summary, stem cell therapy is an exciting field of research for regenerative medicine, particularly for the treatment of cardiovascular diseases. MSCs are a promising cell source because of their ease of isolation and expansion, anti-thrombogenic property, low immunogenicity and potential to differentiate into cardiovascular lineages. In order to utilize MSCs for engineering vascular conduits or as treatment for MI, it is important to understand the role of the microenvironment in modulating MSC behavior and function. In particular, soluble factors, mechanical stimulation and matrix factors all have been shown to stimulate MSC differentiation along cardiovascular lineages in vitro. On the other hand, MSCs can secrete soluble factors and actively participate the remodeling process. The knowledge gained from this two-way signaling process will provide rational basis for the construction of vascular grafts and the treatment of MI.

\section{Future perspective}

Despite the progress made in engineering vascular conduits and in developing stem cell-based therapies for the treatment of MI, the clinical potential of MSCs remains not fully tested. Understanding the role of chemical and physical cues in the regulation of MSC survival, differentiation and tissue formation and the effects of MSCs on the remodeling process will be important for regenerative medicine. For example, optimizing matrix rigidity, chemical composition and mechanical environment that stimulates or sustains cardiovascular cells in both 2D and 3D environments will be important. Furthermore, elucidating the mechanism of their therapeutic effect in vivo will be necessary, as MSCs may be involved in the release of angiogenic factors to diseased tissues as well as in the incorporation into vascular structures. To this end, noninvasive techniques to tracking transplanted cells, such as bioluminescence imaging, MRI and PET, may be beneficial tools. Although autologous cell therapy is preferred in many clinical applications, whether allogenic MSCs can be used to fabricate vascular grafts or other tissue constructs to make them available offthe-shelf needs further investigation. More preclinical trials are necessary to understand the therapeutic effect of allogenic MSC grafts in vivo. Such studies will bring us closer to realizing the therapeutic potential of MSCs for regenerative medicine and cardiovascular tissue engineering.

\section{Executive summary}

\section{Characterization of mesenchymal stem cells}

- Although mesenchymal stem cells (MSCs) occupy only $0.01 \%$ of the total population of nucleated cells in bone marrow, in vitro they have a high expansion ratio of nearly 1 million-fold, while maintaining multilineage differentiation capacity. There is also evidence to show that MSCs have low immunogenicity. 
Currently, the populations referred to as MSCs do not have characteristics or isolation methods that researchers agree upon.

\section{Role of soluble chemical factors}

- Soluble factors such as VEGF, basic FGF, TGF- $\beta$ and PDGF play a role in inducing MSC migration, proliferation and differentiation into vascular cell types.

\section{Role of mechanical factors}

- Shear stress and mechanical strain are mechanical factors that have been shown to stimulate MSC differentiation towards vascular lineages.

- Further research is necessary to elucidate the mechanism of action by which mechanical factors influence MSC fate.

\section{Role of matrix factors}

- Matrix rigidity modulates MSC differentiation towards osteogenic, muscular and neuronal lineages according to the physiological rigidity of respective tissues. However, the role of matrix rigidity on MSC differentiation towards cardiovascular lineages needs further investigation.

- Micropatterning and nanopatterning are useful tools for guiding cell organization and studying the role of restricted cell alignment on MSC differentiation.

\section{Therapeutic potential of MSCs for vascular regeneration}

- MSC-seeded vascular grafts have tremendous therapeutic potential because MSCs have anti-thrombogenic property, can recruit vascular cells through paracrine signaling and can differentiate into vascular lineages.

- For treatment of myocardial infarction, MSCs have been shown to improve cardiac function, differentiate into vascular lineages and stimulate neovasculature formation. The mechanism of action appears to be related to MSC differentiation and the release of angiogenic growth factors.

\section{Bibliography}

Papers of special note have been highlighted as:

- of interest

- of considerable interest

1. Rosamond W, Flegal K, Furie K, et al. Heart disease and stroke statistics - 2008 update: a report from the American Heart Association Statistics Committee and Stroke Statistics Subcommittee. Circulation 2008;117(4):e25-e146. [PubMed: 18086926]

2. Huang NF, Lee RJ, Li S. Chemical and physical regulation of stem cells and progenitor cells: potential for cardiovascular tissue engineering. Tissue Eng 2007;13(8):1809-1823. [PubMed: 17518703]

3. Ross R, Everett NB, Tyler R. Wound healing and collagen formation. VI. The origin of the wound fibroblast studied in parabiosis. J. Cell Biol 1970;44(3):645-654. [PubMed: 5415241]

4. Petrakis NL, Davis M, Lucia SP. The in vivo differentiation of human leukocytes into histiocytes, fibroblasts and fat cells in subcutaneous diffusion chambers. Blood 1961;17:109-118. [PubMed: 13734879]

5. Friedenstein AJ, Gorskaja JF, Kulagina NN. Fibroblast precursors in normal and irradiated mouse hematopoietic organs. Exp. Hematol 1976;4(5):267-274. [PubMed: 976387]

6. Prockop DJ. Marrow stromal cells as stem cells for nonhematopoietic tissues. Science 1997;276(5309): 71-74. [PubMed: 9082988] 
7. Caplan AI. Mesenchymal stem cells. J. Orthop. Res 1991;9(5):641-650. [PubMed: 1870029]

8. Pittenger MF, Mackay AM, Beck SC, et al. Multilineage potential of adult human mesenchymal stem cells. Science 1999;284(5411):143-147. [PubMed: 10102814]

9. Jiang Y, Jahagirdar BN, Reinhardt RL, et al. Pluripotency of mesenchymal stem cells derived from adult marrow. Nature 2002;418(6893):41-49. [PubMed: 12077603]

10. Reyes M, Lund T, Lenvik T, Aguiar D, Koodie L, Verfaillie CM. Purification and ex vivo expansion of postnatal human marrow mesodermal progenitor cells. Blood 2001;98(9):2615-2625. [PubMed: 11675329]

11. Campagnoli C, Roberts IA, Kumar S, Bennett PR, Bellantuono I, Fisk NM. Identification of mesenchymal stem/progenitor cells in human first-trimester fetal blood, liver, and bone marrow. Blood 2001;98(8):2396-2402. [PubMed: 11588036]

12. in 't Anker PS, Noort WA, Scherjon SA, et al. Mesenchymal stem cells in human second-trimester bone marrow, liver, lung, and spleen exhibit a similar immunophenotype but a heterogeneous multilineage differentiation potential. Haematologica 2003;88(8):845-852. [PubMed: 12935972]

13. Bernacki SH, Wall ME, Loboa EG. Isolation of human mesenchymal stem cells from bone and adipose tissue. Methods Cell Biol 2008;86:257-278. [PubMed: 18442651]

14. Pittenger MF, Martin BJ. Mesenchymal stem cells and their potential as cardiac therapeutics. Circ. Res 2004;1(95):9-20. [PubMed: 15242981]

15. Deans RJ, Moseley AB. Mesenchymal stem cells: biology and potential clinical uses. Exp. Hematol 2000;28(8):875-884. [PubMed: 10989188]

16. Simmons PJ, Torok-Storb B. Identification of stromal cell precursors in human bone marrow by a novel monoclonal antibody, STRO-1. Blood 1991;78(1):55-62. [PubMed: 2070060]

17. Peister A, Mellad JA, Larson BL, Hall BM, Gibson LF, Prockop DJ. Adult stem cells from bone marrow (MSCs) isolated from different strains of inbred mice vary in surface epitopes, rates of proliferation, and differentiation potential. Blood 2004;103(5):1662-1668. [PubMed: 14592819]

18. Sobue K, Hayashi K, Nishida W. Expressional regulation of smooth muscle cell-specific genes in association with phenotypic modulation. Mol. Cell Biochem 1999;190(1-2):105-118. [PubMed: 10098977]

19. Kern S, Eichler H, Stoeve J, Kluter H, Bieback K. Comparative analysis of mesenchymal stem cells from bone marrow, umbilical cord blood, or adipose tissue. Stem Cells 2006;24(5):1294-1301. [PubMed: 16410387]

20. Panepucci RA, Siufi JL, Silva WA Jr, et al. Comparison of gene expression of umbilical cord vein and bone marrow-derived mesenchymal stem cells. Stem Cells 2004;22(7):1263-1278. [PubMed: 15579645]

21. Le Blanc K, Tammik C, Rosendahl K, Zetterberg E, Ringden O. HLA expression and immunologic properties of differentiated and undifferentiated mesenchymal stem cells. Exp. Hematol 2003;31(10): 890-896. [PubMed: 14550804]

22. Tse WT, Pendleton JD, Beyer WM, Egalka MC, Guinan EC. Suppression of allogeneic T-cell proliferation by human marrow stromal cells: implications in transplantation. Transplantation 2003;75(3):389-397. [PubMed: 12589164]

23. Di Nicola M, Carlo-Stella C, Magni M, et al. Human bone marrow stromal cells suppress Tlymphocyte proliferation induced by cellular or nonspecific mitogenic stimuli. Blood 2002;99(10): 3838-3843. [PubMed: 11986244]

24. Corcione A, Benvenuto F, Ferretti E, et al. Human mesenchymal stem cells modulate B-cell functions. Blood 2006;107(1):367-372. [PubMed: 16141348]

25. Jiang XX, Zhang Y, Liu B, et al. Human mesenchymal stem cells inhibit differentiation and function of monocyte-derived dendritic cells. Blood 2005;105(10):4120-4126. [PubMed: 15692068]

26. Rasmusson I, Ringden O, Sundberg B, Le Blanc K. Mesenchymal stem cells inhibit lymphocyte proliferation by mitogens and alloantigens by different mechanisms. Exp. Cell Res 2005;1(305):3341. [PubMed: 15777785]

27. Aggarwal S, Pittenger MF. Human mesenchymal stem cells modulate allogeneic immune cell responses. Blood 2005;105(4):1815-1822. [PubMed: 15494428]

28. Ball SG, Shuttleworth CA, Kielty CM. Vascular endothelial growth factor can signal through plateletderived growth factor receptors. J. Cell Biol 2007;177(3):489-500. [PubMed: 17470632] 
29. Lin H, Shabbir A, Molnar M, et al. Adenoviral expression of vascular endothelial growth factor splice variants differentially regulate bone marrow-derived mesenchymal stem cells. J. Cell Physiol 2008;216(2):458-468. [PubMed: 18288639]

30. Fiedler J, Leucht F, Waltenberger J, Dehio C, Brenner RE. VEGF-A and PIGF-1 stimulate chemotactic migration of human mesenchymal progenitor cells. Biochem. Biophys. Res. Commun 2005;334(2): 561-568. [PubMed: 16005848]

31. Schmidt A, Ladage D, Schinkothe T, et al. Basic fibroblast growth factor controls migration in human mesenchymal stem cells. Stem Cells 2006;24(7):1750-1758. [PubMed: 16822883]

32. Chang Y, Lai PH, Wei HJ, et al. Tissue regeneration observed in a basic fibroblast growth factorloaded porous acellular bovine pericardium populated with mesenchymal stem cells. J. Thorac. Cardiovasc. Surg 2007;134(1):65-73. 73 e1-4. [PubMed: 17599488]

33. Wang D, Park JS, Chu JS, et al. Proteomic profi ling of bone marrow mesenchymal stem cells upon transforming growth factor $\beta 1$ stimulation. J. Biol. Chem 2004;42(279):43725-43734. [PubMed: 15302865]

34. Kinner B, Zaleskas JM, Spector M. Regulation of smooth muscle actin expression and contraction in adult human mesenchymal stem cells. Exp. Cell Res 2002;278(1):72-83. [PubMed: 12126959]

35. Ross JJ, Hong Z, Willenbring B, et al. Cytokine-induced differentiation of multipotent adult progenitor cells into functional smooth muscle cells. J. Clin. Invest 2006;116(12):3139-3149. [PubMed: 17099777]

36m. Gong Z, Niklason LE. Small-diameter human vessel wall engineered from bone marrow-derived mesenchymal stem cells (hMSCs). Faseb. J 2008;22(6):1635-1648. [PubMed: 18199698]of considerable interestTissue-engineered arteries containing mesenchymal stem cell (MSC)-derived smooth muscle cells (SMCs) were histologically similar to native vessels.

37. Kurpinski K, Park JS, Thakar RG, Li S. Regulation of vascular smooth muscle cells and mesenchymal stem cells by mechanical strain. Mol. Cell Biomech 2006;3(1):11-24.

38. Li S, Huang NF, Hsu S. Mechanotransduction in endothelial cell migration. J. Cell Biochem 2005;96 (6):1110-1126. [PubMed: 16167340]

39. Lammerding J, Kamm RD, Lee RT. Mechanotransduction in cardiac myocytes. Ann. NY Acad. Sci 2004;1015:53-70. [PubMed: 15201149]

40. Stegemann JP, Hong H, Nerem RM. Mechanical, biochemical, and extracellular matrix effects on vascular smooth muscle cell phenotype. J. Appl. Physiol 2005;98(6):2321-2327. [PubMed: 15894540]

41. Li YS, Haga JH, Chien S. Molecular basis of the effects of shear stress on vascular endothelial cells. J. Biomech 2005;38(10):1949-1971. [PubMed: 16084198]

42. Giddens DP, Zarins CK, Glagov S. The role of fluid mechanics in the localization and detection of atherosclerosis. J. Biomech. Eng 1993;115(4B):588-594. [PubMed: 8302046]

43. Fung, YC. Biodynamics. Springer-Verlag; New York, USA: 1984.

44. Chien S. Effects of disturbed flow on endothelial cells. Ann. Biomed. Eng 2008;36(4):554-562. [PubMed: 18172767]

45. Kobayashi N, Yasu T, Ueba H, et al. Mechanical stress promotes the expression of smooth musclelike properties in marrow stromal cells. Exp. Hematol 2004;32(12):1238-1245. [PubMed: 15588948]

46. Wang H, Riha GM, Yan S, et al. Shear stress induces endothelial differentiation from a murine embryonic mesenchymal progenitor cell line. Arterioscler. Thromb. Vasc. Biol 2005;25(9):18171823. [PubMed: 15994439]

47. Riha GM, Lin PH, Lumsden AB, Yao Q, Chen C. Roles of hemodynamic forces in vascular cell differentiation. Ann. Biomed. Eng 2005;33(6):772-779. [PubMed: 16078617]

48. Park JS, Chu JS, Cheng C, Chen F, Chen D, Li S. Differential effects of equiaxial and uniaxial strain on mesenchymal stem cells. Biotechnol. Bioeng 2004;88(3):359-368. [PubMed: 15486942]

49. Hamilton DW, Maul TM, Vorp DA. Characterization of the response of bone marrow-derived progenitor cells to cyclic strain: implications for vascular tissue-engineering applications. Tissue Eng 2004;10(3-4):361-369. [PubMed: 15165453]

50. Kurpinski K, Chu J, Hashi C, Li S. Anisotropic mechanosensing by mesenchymal stem cells. Proc. Natl Acad. Sci. USA 2006;103(44):16095-16100. [PubMed: 17060641] 
51. O'Cearbhaill ED, Punchard MA, Murphy M, Barry FP, McHugh PE, Barron V. Response of mesenchymal stem cells to the biomechanical environment of the endothelium on a flexible tubular silicone substrate. Biomaterials 2008;29(11):1610-1619. [PubMed: 18194813]

52. Engelmayr GC Jr, Sales VL, Mayer JE Jr, Sacks MS. Cyclic flexure and laminar flow synergistically accelerate mesenchymal stem cell-mediated engineered tissue formation: Implications for engineered heart valve tissues. Biomaterials 2006;27(36):6083-6095. [PubMed: 16930686]

53. Kleinman HK, Martin GR. Matrigel: basement membrane matrix with biological activity. Semin. Cancer Biol 2005;15(5):378-386. [PubMed: 15975825]

54. Flaim CJ, Chien S, Bhatia SN. An extracellular matrix microarray for probing cellular differentiation. Nat. Methods 2005;2(2):119-125. [PubMed: 15782209]

55. Schmidt CE, Baier JM. Acellular vascular tissues: natural biomaterials for tissue repair and tissue engineering. Biomaterials 2000;21(22):2215-2231. [PubMed: 11026628]

56. Sierra DH. Fibrin sealant adhesive systems: a review of their chemistry, material properties and clinical applications. J. Biomater. Appl 1993;7(4):309-352. [PubMed: 8473984]

57. Morra M. Engineering of biomaterials surfaces by hyaluronan. Biomacromolecules 2005;6(3):12051223. [PubMed: 15877335]

58. Wu X, Rabkin-Aikawa E, Guleserian KJ, et al. Tissue-engineered microvessels on three-dimensional biodegradable scaffolds using human endothelial progenitor cells. Am. J. Physiol. Heart Circ. Physiol 2004;287(2):H480-H487. [PubMed: 15277191]

59. Wu, XS. Encyclopedic Handbook of Biomaterials and Bioengineering, Part A: Materials. Marcel Dekker; New York, USA: 1995.

60. Wu XS, Wang N. Synthesis, characterization, biodegradation, and drug delivery application of biodegradable lactic/glycolic acid polymers. Part II: biodegradation. J. Biomater. Sci. Polym. Ed 2001;12(1):21-34. [PubMed: 11334187]

61. Christman KL, Lee RJ. Biomaterials for the treatment of myocardial infarction. J. Am. Coll. Cardiol 2006;48(5):907-913. [PubMed: 16949479]

62. Zisch AH, Lutolf MP, Hubbell JA. Biopolymeric delivery matrices for angiogenic growth factors. Cardiovasc. Pathol 2003;12(6):295-310. [PubMed: 14630296]

63. Levenberg S, Huang NF, Lavik E, Rogers AB, Itskovitz-Eldor J, Langer R. Differentiation of human embryonic stem cells on three-dimensional polymer scaffolds. Proc. Natl Acad. Sci. USA 2003;100 (22):12741-12746. [PubMed: 14561891]

64. Huang NF, Yu J, Sievers R, Li S, Lee RJ. Injectable biopolymers enhance angiogenesis after myocardial infarction. Tissue Eng 2005;11(11-12):1860-1866. [PubMed: 16411832]

65. Park JS, Huang NF, Kurpinski KT, Patel S, Hsu S, Li S. Mechanobiology of mesenchymal stem cells and their use in cardiovascular repair. Front. Biosci 2007;12:5098-5116. [PubMed: 17569633]

66. Geiger B, Bershadsky A, Pankov R, Yamada KM. Transmembrane crosstalk between the extracellular matrix - cytoskeleton crosstalk. Nat Rev. Mol. Cell Biol 2001;2(11):793-805. [PubMed: 11715046]

67. Chastain SR, Kundu AK, Dhar S, Calvert JW, Putnam AJ. Adhesion of mesenchymal stem cells to polymer scaffolds occurs via distinct ECM ligands and controls their osteogenic differentiation. J. Biomed. Mater. Res. A 2006;78(1):73-85. [PubMed: 16602124]

68. Majumdar MK, Keane-Moore M, Buyaner D, et al. Characterization and functionality of cell surface molecules on human mesenchymal stem cells. J. Biomed. Sci 2003;10(2):228-241. [PubMed: 12595759]

69. Critchley DR. Focal adhesions - the cytoskeletal connection. Curr. Opin. Cell Biol 2000;12(1):133139. [PubMed: 10679361]

70. Pelham RJ Jr, Wang Y. Cell locomotion and focal adhesions are regulated by substrate flexibility. Proc. Natl Acad. Sci. USA 1997;94(25):13661-13665. [PubMed: 9391082]

71. Yeung T, Georges PC, Flanagan LA, et al. Effects of substrate stiffness on cell morphology, cytoskeletal structure, and adhesion. Cell Motil. Cytoskeleton 2005;60(1):24-34. [PubMed: 15573414]

72. Lo CM, Wang HB, Dembo M, Wang YL. Cell movement is guided by the rigidity of the substrate. Biophys. J 2000;79(1):144-152. [PubMed: 10866943] 
73m. Engler AJ, Sen S, Sweeney HL, Discher DE. Matrix elasticity directs stem cell lineage specification. Cell 2006;126(4):677-689. [PubMed: 16923388] of interestSubstrate rigidity can modulate MSC differentiation into neurogenic, myogenic and osteogenic lineages.

74. Singhvi R, Kumar A, Lopez GP, et al. Engineering cell shape and function. Science 1994;264(5159): 696-698. [PubMed: 8171320]

75. Thakar RG, Ho F, Huang NF, Liepmann D, Li S. Regulation of vascular smooth muscle cells by micropatterning. Biochem. Biophys. Res. Commun 2003;307(4):883-890. [PubMed: 12878194]

76. Huang NF, Patel S, Thakar RG, et al. Myotube assembly on nanofibrous and micropatterned polymers. Nano Lett 2006;6(3):537-542. [PubMed: 16522058]

77. McBeath R, Pirone DM, Nelson CM, Bhadriraju K, Chen CS. Cell shape, cytoskeletal tension, and RhoA regulate stem cell lineage commitment. Dev. Cell 2004;6(4):483-495. [PubMed: 15068789]

78. Li WJ, Laurencin CT, Caterson EJ, Tuan RS, Ko FK. Electrospun nanofibrous structure: a novel scaffold for tissue engineering. J. Biomed. Mater. Res 2002;60(4):613-621. [PubMed: 11948520]

79. Xu CY, Inai R, Kotaki M, Ramakrishna S. Aligned biodegradable nanofibrous structure: a potential scaffold for blood vessel engineering. Biomaterials 2004;25(5):877-886. [PubMed: 14609676]

80. Patel S, Kurpinski K, Quigley R, et al. Bioactive nanofibers: synergistic effects of nanotopography and chemical signaling on cell guidance. Nano Lett 2007;7(7):2122-2128. [PubMed: 17567179]

81. Hashi CK, Zhu Y, Yang GY, et al. Antithrombogenic property of bone marrow mesenchymal stem cells in nanofibrous vascular grafts. Proc. Natl Acad. Sci. USA 2007;104(29):11915-11920. [PubMed: 17615237] of interestMSC-seeded nanoporous vascular grafts exhibited long-term patency and organized layers of endothelial cells and SMCs.

82. Zdrahala RJ. Small caliber vascular grafts. Part I: state of the art. J. Biomater. Appl 1996;10(4):309329. [PubMed: 8859403]

83. Zdrahala RJ. Small caliber vascular grafts. Part II: Polyurethanes revisited. J. Biomater. Appl 1996;11 (1):37-61. [PubMed: 8872599]

84. Weinberg CB, Bell E. A blood vessel model constructed from collagen and cultured vascular cells. Science 1986;231(4736):397-400. [PubMed: 2934816]

85. Matsuda T, Miwa H. A hybrid vascular model biomimicking the hierarchic structure of arterial wall: neointimal stability and neoarterial regeneration process under arterial circulation. J. Thorac. Cardiovasc. Surg 1995;110(4 Pt 1):988-997. [PubMed: 7475165]

86. L'Heureux N, Paquet S, Labbe R, Germain L, Auger FA. A completely biological tissue-engineered human blood vessel. Faseb. J 1998;12(1):47-56. [PubMed: 9438410]

87. Niklason LE, Gao J, Abbott WM, et al. Functional arteries grown in vitro. Science 1999;284(5413): 489-493. [PubMed: 10205057]

88. Seliktar D, Black RA, Vito RP, Nerem RM. Dynamic mechanical conditioning of collagen-gel blood vessel constructs induces remodeling in vitro. Ann. Biomed. Eng 2000;28(4):351-362. [PubMed: 10870892]

89. L'Heureux N, Dusserre N, Konig G, et al. Human tissue-engineered blood vessels for adult arterial revascularization. Nat. Med 2006;12(3):361-365. [PubMed: 16491087]

90. Mirza A, Hyvelin JM, Rochefort GY, et al. Undifferentiated mesenchymal stem cells seeded on a vascular prosthesis contribute to the restoration of a physiologic vascular wall. J. Vasc. Surg 2008;47 (6):1313-1321. [PubMed: 18329228]

91. Kanki-Horimoto S, Horimoto H, Mieno S, et al. Synthetic vascular prosthesis impregnated with mesenchymal stem cells overexpressing endothelial nitric oxide synthase. Circulation 2006;114 (Suppl 1):I327-I330. [PubMed: 16820594]

92. Zhang L, Zhou J, Lu Q, Wei Y, Hu S. A novel small-diameter vascular graft: in vivo behavior of biodegradable three-layered tubular scaffolds. Biotechnol. Bioeng 2008;99(4):1007-1015. [PubMed: 17705246]

93. Schmidt SP, Hunter TJ, Sharp WV, Malindzak GS, Evancho MM. Endothelial cell - seeded fourmillimeter Dacron vascular grafts: effects of blood flow manipulation through the grafts. J. Vasc. Surg 1984;1(3):434-441. [PubMed: 6237211]

94. Kempczinski RF, Rosenman JE, Pearce WH, Roedersheimer LR, Berlatzky Y, Ramalanjaona G. Endothelial cell seeding of a new PTFE vascular prosthesis. J. Vasc. Surg 1985;2(3):424-429. [PubMed: 3999233] 
95. Bhattacharya V, McSweeney PA, Shi Q, et al. Enhanced endothelialization and microvessel formation in polyester grafts seeded with CD34+ ${ }^{+}$bone marrow cells. Blood 2000;95(2):581-585. [PubMed: 10627466]

96. Kaushal S, Amiel GE, Guleserian KJ, et al. Functional small-diameter neovessels created using endothelial progenitor cells expanded ex vivo. Nat. Med 2001;7(9):1035-1040. [PubMed: 11533707]

97. Shirota T, He H, Yasui H, Matsuda T. Human endothelial progenitor cell-seeded hybrid graft: proliferative and antithrombogenic potentials in vitro and fabrication processing. Tissue Eng 2003;9 (1):127-136. [PubMed: 12625961]

98. Griese DP, Ehsan A, Melo LG, et al. Isolation and transplantation of autologous circulating endothelial cells into denuded vessels and prosthetic grafts: implications for cell-based vascular therapy. Circulation 2003;108(21):2710-2715. [PubMed: 14597586]

99. Maeda M, Fukui A, Nakamura T, et al. Progenitor endothelial cells on vascular grafts: an ultrastructural study. J. Biomed. Mater. Res 2000;51(1):55-60. [PubMed: 10813745]

100. Shi Q, Rafii S, Wu MH, et al. Evidence for circulating bone marrow-derived endothelial cells. Blood 1998;92(2):362-367. [PubMed: 9657732]

101. Anversa P, Li P, Zhang X, Olivetti G, Capasso JM. Ischaemic myocardial injury and ventricular remodelling. Cardiovasc. Res 1993;27(2):145-157. [PubMed: 8472264]

102. Mann DL. Mechanisms and models in heart failure: A combinatorial approach. Circulation 1999;100 (9):999-1008. [PubMed: 10468532]

103. Sun Y, Weber KT. Infarct scar: a dynamic tissue. Cardiovasc. Res 2000;46(2):250-256. [PubMed: 10773228]

104. Papetti M, Herman IM. Mechanisms of normal and tumor-derived angiogenesis. Am. J. Physiol. Cell Physiol 2002;282(5):C947-C970. [PubMed: 11940508]

105. Soonpaa MH, Koh GY, Klug MG, Field LJ. Formation of nascent intercalated disks between grafted fetal cardiomyocytes and host myocardium. Science 1994;5155(264):98-101. [PubMed: 8140423]

106. Murry CE, Wiseman RW, Schwartz SM, Hauschka SD. Skeletal myoblast transplantation for repair of myocardial necrosis. J. Clin. Invest 1996;98(11):2512-2523. [PubMed: 8958214]

107. Kofidis T, Lebl DR, Martinez EC, Hoyt G, Tanaka M, Robbins RC. Novel injectable bioartificial tissue facilitates targeted, less invasive, large-scale tissue restoration on the beating heart after myocardial injury. Circulation 2005;112(Suppl 9):I173-I177. [PubMed: 16159811]

108. Toma C, Pittenger MF, Cahill KS, Byrne BJ, Kessler PD. Human mesenchymal stem cells differentiate to a cardiomyocyte phenotype in the adult murine heart. Circulation 2002;105(1):9398. [PubMed: 11772882]

109. Richardson TP, Peters MC, Ennett AB, Mooney DJ. Polymeric system for dual growth factor delivery. Nat. Biotechnol 2001;19(11):1029-1034. [PubMed: 11689847]

110. Silva GV, Litovsky S, Assad JA, et al. Mesenchymal stem cells differentiate into an endothelial phenotype, enhance vascular density, and improve heart function in a canine chronic ischemia model. Circulation 2005;111(2):150-156. [PubMed: 15642764]

111. Schuleri KH, Amado LC, Boyle AJ, et al. Early improvement in cardiac tissue perfusion due to mesenchymal stem cells. Am. J. Physiol. Heart Circ. Physiol 2008;294(5):H2002-H2011. [PubMed: 18310523]

112. Grauss RW, Winter EM, van Tuyn J, et al. Mesenchymal stem cells from ischemic heart disease patients improve left ventricular function after acute myocardial infarction. Am. J. Physiol. Heart Circ. Physiol 2007;293(4):H2438-H2447. [PubMed: 17644573]

113. Amsalem Y, Mardor Y, Feinberg MS, et al. Iron-oxide labeling and outcome of transplanted mesenchymal stem cells in the infarcted myocardium. Circulation 2007;116(Suppl 11):I38-I45. [PubMed: 17846324]

114. Zhang M, Mal N, Kiedrowski M, et al. SDF-1 expression by mesenchymal stem cells results in trophic support of cardiac myocytes after myocardial infarction. Faseb. J 2007;21(12):3197-3207. [PubMed: 17496162]

115. Dai W, Hale SL, Martin BJ, et al. Allogeneic mesenchymal stem cell transplantation in postinfarcted rat myocardium: short- and long-term effects. Circulation 2005;112(2):214-223. [PubMed: 15998673] 
116. Alvarez-Dolado M, Pardal R, Garcia-Verdugo JM, et al. Fusion of bone-marrow-derived cells with Purkinje neurons, cardiomyocytes and hepatocytes. Nature 2003;425(6961):968-973. [PubMed: 14555960]

117. Terada N, Hamazaki T, Oka M, et al. Bone marrow cells adopt the phenotype of other cells by spontaneous cell fusion. Nature 2002;416(6880):542-545. [PubMed: 11932747]

118. Kajstura J, Rota M, Whang B, et al. Bone marrow cells differentiate in cardiac cell lineages after infarction independently of cell fusion. Circ. Res 2005;96(1):127-137. [PubMed: 15569828]

119m. Miyahara Y, Nagaya N, Kataoka M, et al. Monolayered mesenchymal stem cells repair scarred myocardium after myocardial infarction. Nat. Med 2006;12(4):459-465. [PubMed: 16582917] of considerable interestEngrafted sheets of MSCs on the epicardial surface of the heart could stimulate neovascularization and differentiation of vascular lineages.

120. Wang CC, Chen CH, Lin WW, et al. Direct intramyocardial injection of mesenchymal stem cell sheet fragments improves cardiac functions after infarction. Cardiovasc. Res 2008;77(3):515-524. [PubMed: 18006453]

121. Kinnaird T, Stabile E, Burnett MS, et al. Local delivery of marrow-derived stromal cells augments collateral perfusion through paracrine mechanisms. Circulation 2004;109(12):1543-1549. [PubMed: 15023891]

122. Tang YL, Zhao Q, Qin X, et al. Paracrine action enhances the effects of autologous mesenchymal stem cell transplantation on vascular regeneration in rat model of myocardial infarction. Ann. Thorac. Surg 2005;80(1):229-236. [PubMed: 15975372]discussion 236-227

123. Simpson D, Liu H, Fan TH, Nerem R, Dudley SC Jr. A tissue engineering approach to progenitor cell delivery results in significant cell engraftment and improved myocardial remodeling. Stem Cells 2007;25(9):2350-2357. [PubMed: 17525236]

124. Wei HJ, Chen CH, Lee WY, et al. Bioengineered cardiac patch constructed from multilayered mesenchymal stem cells for myocardial repair. Biomaterials 2008;29(26):3547-3556. [PubMed: 18538386]

125. Huang NF, Sievers RE, Park JS, Fang Q, Li S, Lee RJ. A rodent model of myocardial infarction for testing the efficacy of cells and polymers for myocardial reconstruction. Nat. Protoc 2006;1(3): 1596-1609. [PubMed: 17406452]

126m. Mangi AA, Noiseux N, Kong D, et al. Mesenchymal stem cells modified with Akt prevent remodeling and restore performance of infarcted hearts. Nat. Med 2003;9(9):1195-1201. [PubMed: 12910262] of considerable interestDelivery of Akt-modified MSCs could reduce intramyocardial inflammation and collagen deposition, while regenerating lost myocardial volume and normalizing cardiac function.

127. Liu XH, Bai CG, Xu ZY, et al. Therapeutic potential of angiogenin modified mesenchymal stem cells: angiogenin improves mesenchymal stem cells survival under hypoxia and enhances vasculogenesis in myocardial infarction. Microvasc. Res 2008;76(1):23-30. [PubMed: 18462761]

128. Li W, Ma N, Ong LL, et al. Bcl-2 engineered MSCs inhibited apoptosis and improved heart function. Stem Cells 2007;25(8):2118-2127. [PubMed: 17478584]

129. Hu X, Yu SP, Fraser JL, et al. Transplantation of hypoxia-preconditioned mesenchymal stem cells improves infarcted heart function via enhanced survival of implanted cells and angiogenesis. J. Thorac. Cardiovasc. Surg 2008;135(4):799-808. [PubMed: 18374759]

130. Fiedler J, Roderer G, Gunther KP, Brenner RE. BMP-2, BMP-4, and PDGF-bb stimulate chemotactic migration of primary human mesenchymal progenitor cells. J. Cell Biochem 2002;87(3):305-312. [PubMed: 12397612]

131. Kinnaird T, Stabile E, Burnett MS, et al. Marrow-derived stromal cells express genes encoding a broad spectrum of arteriogenic cytokines and promote in vitro and in vivo arteriogenesis through paracrine mechanisms. Circ. Res 2004;94(5):678-685. [PubMed: 14739163]

132. Gnecchi M, He H, Noiseux N, et al. Evidence supporting paracrine hypothesis for Akt-modified mesenchymal stem cell-mediated cardiac protection and functional improvement. Faseb. J 2006;20 (6):661-669. [PubMed: 16581974]

133. Zhang J, Qi H, Wang H, et al. Engineering of vascular grafts with genetically modified bone marrow mesenchymal stem cells on poly (propylene carbonate) graft. Artif. Organs 2006;30(12):898-905. [PubMed: 17181830] 


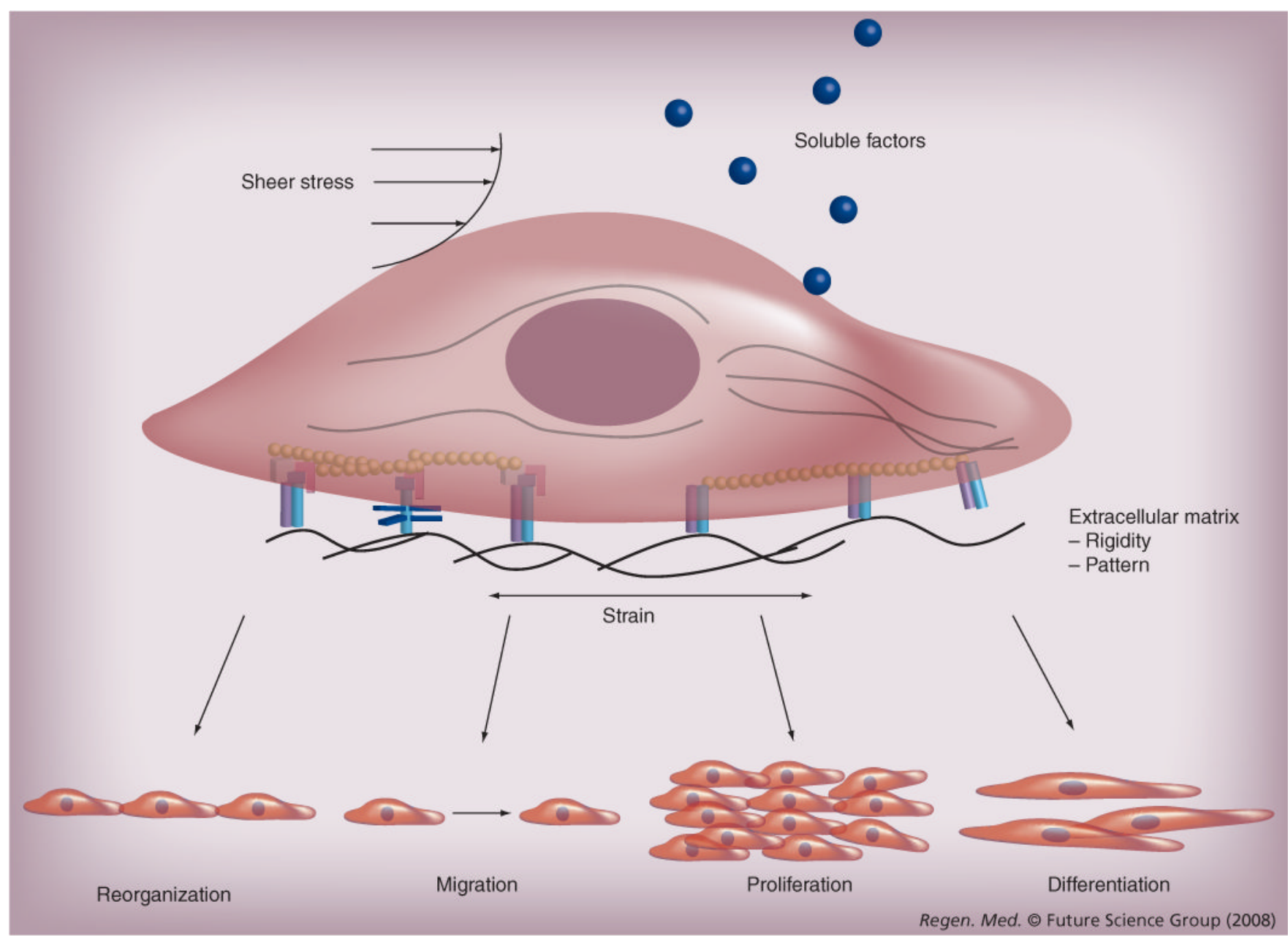

Figure 1.

Multifaceted microenvironmental factors can affect mesenchymal stem cell phenotype and behavior. 


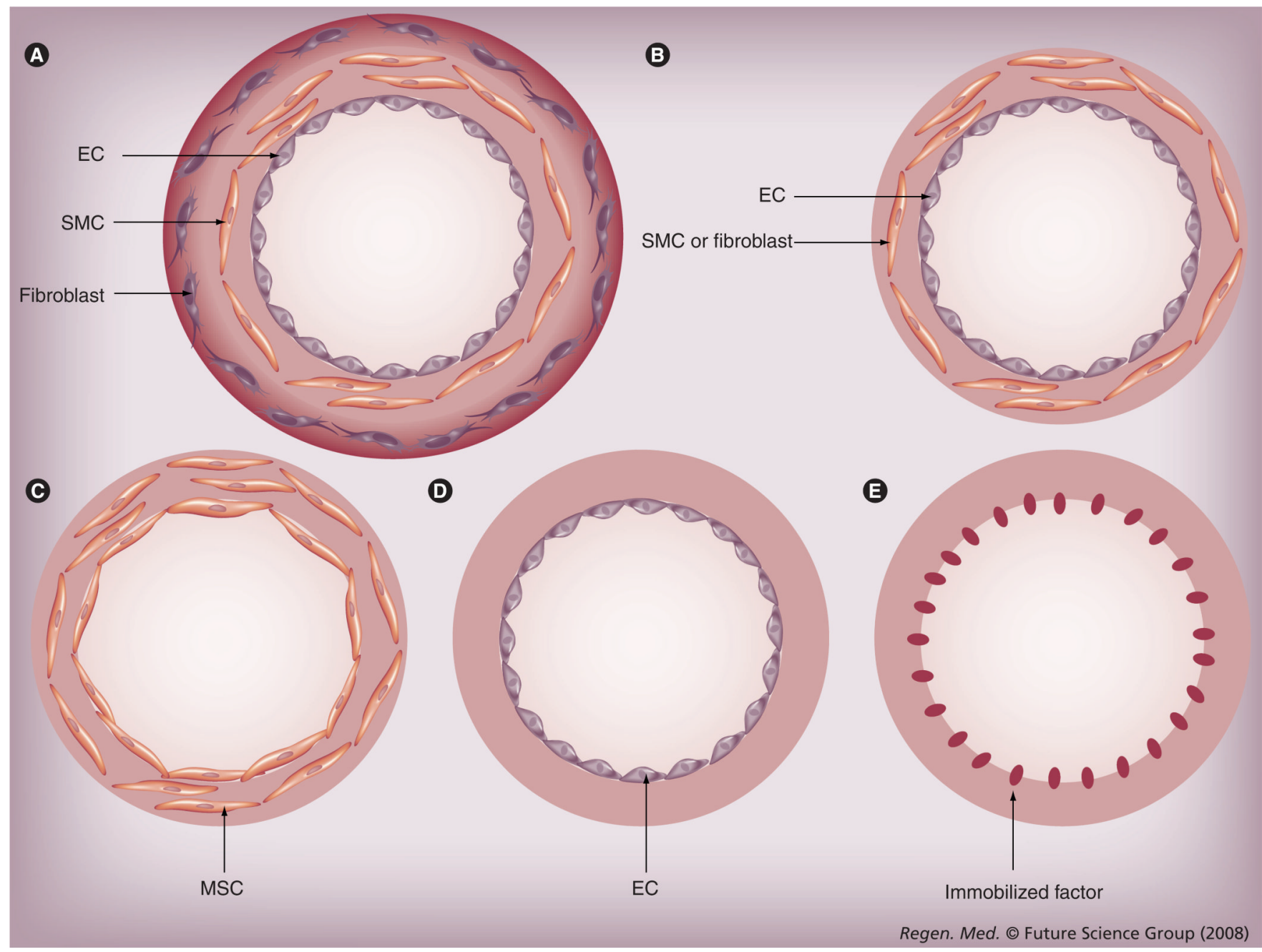

Figure 2. Models of vascular graft construction

(A) Three-layer model using ECs, SMCs and fibroblasts. (B) Two-layer model using ECs and SMCs/fibroblasts. (C) One-layer model using MSCs. (D) One-layer model using ECs. (E) Acellular model with immobilized factors.

EC: Endothelial cell; EPC: Endothelial progenitor cell; MSC: Mesenchymal stem cell; SMC: Smooth muscle cell. 


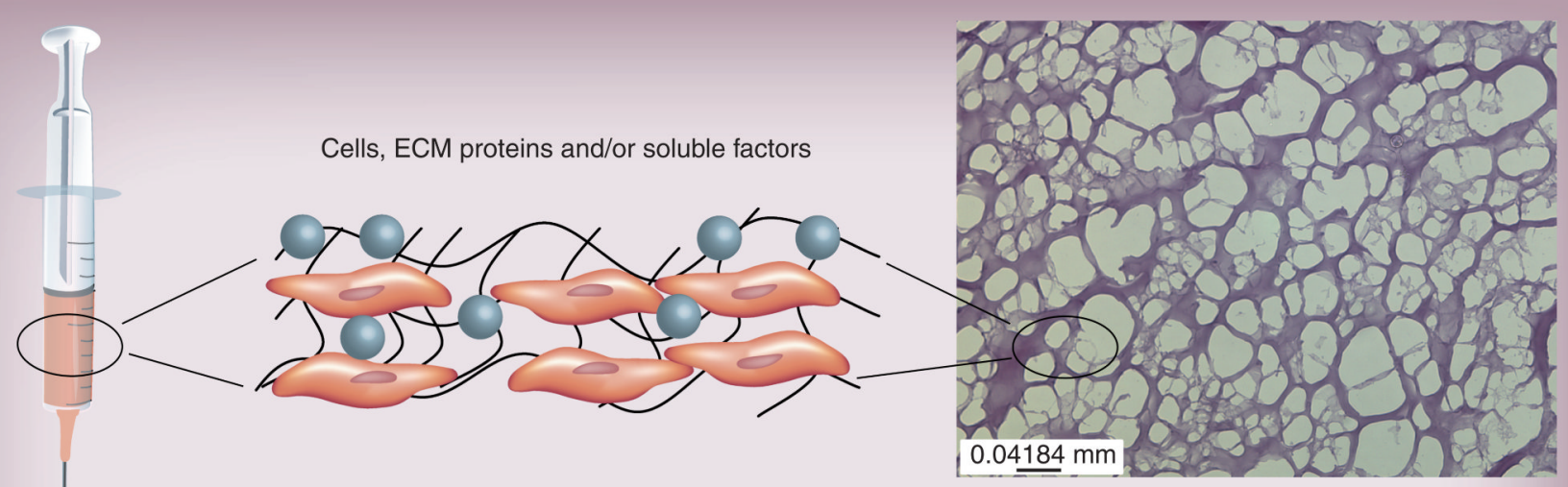

Ischemic mycocardium

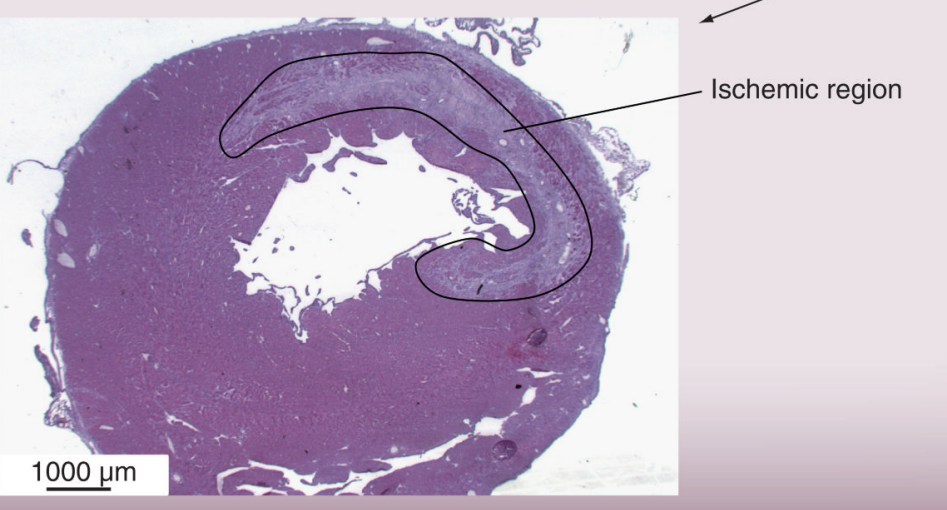

Figure 3. Models of cardiovascular repair

For treatment of the ischemic myocardium, cells and other factors can be injected directly to the center or border zone of the infarct. Alternatively, the cells can be transplanted as an epicardial patch using porous matrices such as fibrin. The solid line indicates the borders of the infarcted region.

ECM: Extracellular matrix. 
Table 1

The effect of chemical factors on mesenchymal stem cell migration, proliferation and differentiation.

\begin{tabular}{|c|c|c|}
\hline Chemical factor & Effect & Ref. \\
\hline VEGF & $\begin{array}{l}\text { Increases migration } \\
\text { Increases proliferation } \\
\text { Induces EC differentiation }\end{array}$ & [28-31] \\
\hline PDGF & $\begin{array}{l}\text { Increases migration } \\
\text { Increases proliferation }\end{array}$ & {$[28,130]$} \\
\hline$\overline{\mathrm{bFGF}}$ & $\begin{array}{l}\text { Increases migration } \\
\text { Induces EC differentiation } \\
\text { Induces SMC differentiation }\end{array}$ & {$[31,32]$} \\
\hline TGF- $\beta$ & Induces SMC differentiation & $\overline{[33-36]}$ \\
\hline
\end{tabular}

bFGF: Basic FGF; EC: Endothelial cell; SMC: Smooth muscle cell. 
Table 2

Angiogenic factors produced by mesenchymal stem cells.

\begin{tabular}{|c|c|c|}
\hline Factor & Induction with hypoxia $\left(\leq 1 \% \mathrm{O}_{2}\right)$ & Ref. \\
\hline Angiopoietin-1 & - & [131] \\
\hline bFGF & + & {$[131,132]$} \\
\hline HGF & + & [132] \\
\hline IL-1 & + & [131] \\
\hline IL-6 & + & [131] \\
\hline IGF-1 & - & {$[132]$} \\
\hline MCP-1 & - & {$[131]$} \\
\hline M-CSF & - & {$[131]$} \\
\hline PIGF & + & [131] \\
\hline$\overline{\text { PDGF }}$ & $\overline{-}$ & $\overline{[131]}$ \\
\hline TGF- $\beta$ & + & $\overline{[131]}$ \\
\hline VEGF-A & + & {$[131,132]$} \\
\hline VEGF-B & - & {$[131]$} \\
\hline
\end{tabular}

+: Induced in the presence of hypoxia; -:Not induced in the presence of hypoxia.

bFGF: Basic FGF; MCP: Monocyte chemoattractant protein; M-CSF: Macrophage-specific colony stimulating factor. 
Table 3

The effect of mechanical factors on mesenchymal stem cells for vascular differentiation.

\begin{tabular}{|c|c|c|}
\hline Mechanical stimulation & Effect & Ref. \\
\hline Shear stress & $\begin{array}{l}\text { Promotes EC differentiation } \\
\text { Promotes SMC differentiation }\end{array}$ & $\begin{array}{l}{[46]} \\
{[45]}\end{array}$ \\
\hline Strain & $\begin{array}{l}\text { Promotes SMC differentiation } \\
\text { Inhibits SMC differentiation }\end{array}$ & $\begin{array}{r}{[48,50]} \\
{[49]}\end{array}$ \\
\hline Shear stress and cyclic strain & $\begin{array}{l}\text { Promotes collagen deposition } \\
\text { Promotes SMC differentiation }\end{array}$ & $\begin{array}{l}{[52]} \\
{[51]}\end{array}$ \\
\hline
\end{tabular}

EC: Endothelial cell; SMC: Smooth muscle cell. 
Table 4

The therapeutic potential of mesenchymal stem cells in in vivo for repair of myocardial infarction and vascular tissue engineering.

\begin{tabular}{lll}
\hline Application & Area of Improvement & Ref. \\
\hline Vascular graft & Vascular differentiation & {$[90,92]$} \\
& Anti-thrombogenesis & {$[81,91,133]$} \\
\cline { 3 - 4 } Myocardial infarction & Neovascularization & {$[110-112,119,120,122,124,127,128]$} \\
& Cardiac function & {$[110-112,120,122,123]$} \\
& Vascular differentiation & {$[110,112,119,120,124]$} \\
& Survival of transplanted cells & {$[126-129]$} \\
\hline
\end{tabular}

